\title{
Diazinon Toxicosis in Geese
}

\author{
Béla Fazekas ${ }^{*}$, , Éva Ivanics ${ }^{1}$, István Hajtós ${ }^{2}$ and Róbert Glávits ${ }^{1}$ \\ ${ }^{1}$ Central Agricultural Office, Veterinary Diagnostic Directorate, Budapest, Hungary \\ ${ }^{2}$ Agricultural Office of Borsod-Abaúj-Zemplén County, Food Safety and Animal Health Directorate, Miskolc, Hungary
}

\begin{abstract}
On a goose farm with 7600 geese kept in 6 houses, 730 birds in 2 houses died within a single day. After drinking, a certain proportion of geese in the affected houses exhibited trembling, salivation, lachrymation and respiratory distress followed by convulsions, dullness and prostration. The birds died soon after the onset of clinical signs. Postmortem examination revealed the presence of a large volume of watery content in the crop. The mucous membrane of the intestinal tract and the parenchymal organs were hyperaemic. Histopathological examination demonstrated the signs of circulatory disturbances in the inner organs. Water samples showing milk-like whitish discolouration, taken from the watering troughs of the two affected houses, were assayed by gas chromatography-mass spectrometry (GC-MS) and found to contain diazinon in concentrations of 807 and $582 \mathrm{mg} / \mathrm{l}$, respectively. In the oesophageal content of the dead geese GC-MS demonstrated diazinon in concentrations of 22.1 and $9.3 \mathrm{mg} / \mathrm{kg}$, respectively. On the basis of these results the diagnosis of poisoning caused by the organophosphate insecticide diazinon was established. The suspicion of accidental or intentional contamination of the drinking water with a diazinon-containing product has arisen, but attempts to identify the diazinoncontaining product responsible for the toxicosis were unsuccessful.
\end{abstract}

Keywords: Diazinon, organophosphate, pesticide, goose, toxicosis, poisoning.

\section{INTRODUCTION}

Diazinon is a very highly toxic organophosphate compound. Organophosphates are long known and widely applied active ingredients of different insecticides used in the plant protection practice. In animal production these compounds are used to control a variety of ectoparasites such as mites and lice. In the living organism, organophosphates inhibit the enzyme acetylcholinesterase, causing an accumulation of acetylcholine, a neurotransmitter involved in impulse transmission, and leading to an over-stimulation of the parasympathetic nerves [1]. Poisoned animals show salivation, lachrymation, diarrhoea and convulsions followed by depression, prostration, ataxia and cyanosis, and then death usually ensues within a short time. Avian species are more susceptible to the toxic effects of diazinon than are mammals. Poisoned chickens often exhibit only respiratory distress, lachrymation and salivation before death, and therefore the suspicion of an acute respiratory infection may also arise [2].

The diazinon toxicity has been reported in very many avian species [3,4]. There are reports in the scientific literature of natural outbreaks in wild geese [5] and goslings [6].

During a recent episode, in a Northern Hungarian flock comprising 7600 breeder geese a total of 730 birds died of diazinon poisoning within 24 hours. This paper reports the observations made and examinations performed during the investigation of this case of poisoning.

*Address correspondence to this author at the Central Agricultural Office, Veterinary Diagnostic Directorate, Tábornok u. 2, H-1149 Budapest, Hungary; Tel: 36-1460-6300; Fax: 36-1252-5177; E-mail: fazekasb@oai.hu

\section{MATERIALS AND METHODOLOGY}

\section{Laboratory Examinations}

Ten goose carcasses and samples of discoloured drinking water from watering troughs were submitted for laboratory examination from each of the two affected houses.

Post-mortem examination of the goose carcasses, histopathological examination of their selected organs (brain, liver, kidney, heart, pancreas) and bacterial culture from the livers were done according to the standard diagnostic procedures practised in the institute.

During the toxicological analysis of samples from the oesophageal content and drinking water, extraction and sample cleanup were done using procedures suitable for the identification of organophosphates. For the instrumental analysis a gas chromatograph equipped with a mass spectrometric detector (AutoSystem XL-TurboMass GC-MS) was used. Gas chromatographic separation was done using a PE-35 MS type column (length $30 \mathrm{~m}$, diameter $0.32 \mathrm{~mm}$, film thickness $0.25 \mu \mathrm{m}$ ). The analysis employed a temperature programme optimised for the separation of organophosphate esters. For mass spectrometric detection we used electron ionisation $(\mathrm{EI}+; 70 \mathrm{eV})$. The mass spectrometric detector was operated in scan mode (range: $50-400 \mathrm{~m} / \mathrm{z}$ ) and selected ion mode (SIM). Diazinon was identified on the basis of the standard retention time and the mass spectrum. With the help of a software (TurboMass), the obtained mass spectrum was compared to mass spectra available in the NIST, NBS and Pfleger libraries. For the quantitative analysis an internal standard was used. 


\section{RESULTS}

\section{Case Report}

In a flock of 7600 one-year-old breeder geese kept in 6 separate houses on a farmstead in Borsod-Abaúj-Zemplén County, about 15 minutes after the morning feeding and watering of geese in two houses $(n=1300$ and 1200, respectively) a certain proportion of the birds showed trembling, salivation, lachrymation and respiratory distress followed by convulsions, dullness and prostration. Within a short time, deaths also occurred. About 700 geese died during the day and a further 30 during the following night (total: 730 deaths).

During the subsequent days no further mortalities occurred. No such toxicosis symptoms were observed in the other four houses. The drinking water in the watering troughs belonging to the two affected houses showed milklike, whitish discolouration. The drinking from these watering troughs was immediately suspended when the poisoning was suspected.

\section{Post-Mortem Findings}

The 10 goose carcasses subjected to post-mortem examination showed similar lesions. The crop contained a large volume of thin, yellowish-white, mucous-watery content of characteristic odour. A smaller volume of similar content could be found in the proventriculus. The gizzard contained mash feed and pebbles. The mucous membrane of the intestinal tract was hyperaemic, showed vascular injection and in some segments - especially in the small intestine - it was dark red and covered by catarrhal mucus. The parenchymal organs were hyperaemic and the liver was slightly swollen.
The blood was flowing and not clotted. The other organs, the serous membranes and the skeletal muscles were without pathological lesions.

\section{Histopathological Examination}

Histopathological examination demonstrated changes indicative of acute circulatory disturbance, passive congestive hyperaemia and, occasionally, mild interstitial oedema was observed in the brain, liver, kidney, heart and pancreas of the goose carcasses.

\section{Microbiological Examination}

Attempts to culture bacteria from the organs were unsuccessful. Viral infections were ruled out on the basis of history, clinical signs, and gross and microscopic pathology.

\section{Toxicological Analysis}

The oesophageal content of the two goose carcasses subjected to toxicological analysis contained $22.1 \mathrm{mg} / \mathrm{kg}$ and $9.3 \mathrm{mg} / \mathrm{kg}$ diazinon, respectively, while in the drinking water samples originating from the two affected houses $807 \mathrm{mg} / \mathrm{l}$ and $582 \mathrm{mg} / \mathrm{l}$ diazinon concentrations, respectively, were found. The identity of diazinon was confirmed by the identity of the mass spectrum and the retention time. The chromatogram obtained by the GC-MS analysis of the oesophageal content of one of the goose carcasses is shown in Fig. (1), while the mass spectrum of diazinon is presented in Fig. (2).

\section{DISCUSSION}

In the case reported in this paper, the course of disease occurring in the goose flock, the daily mortality curve and the observed clinical signs and pathomorphological changes

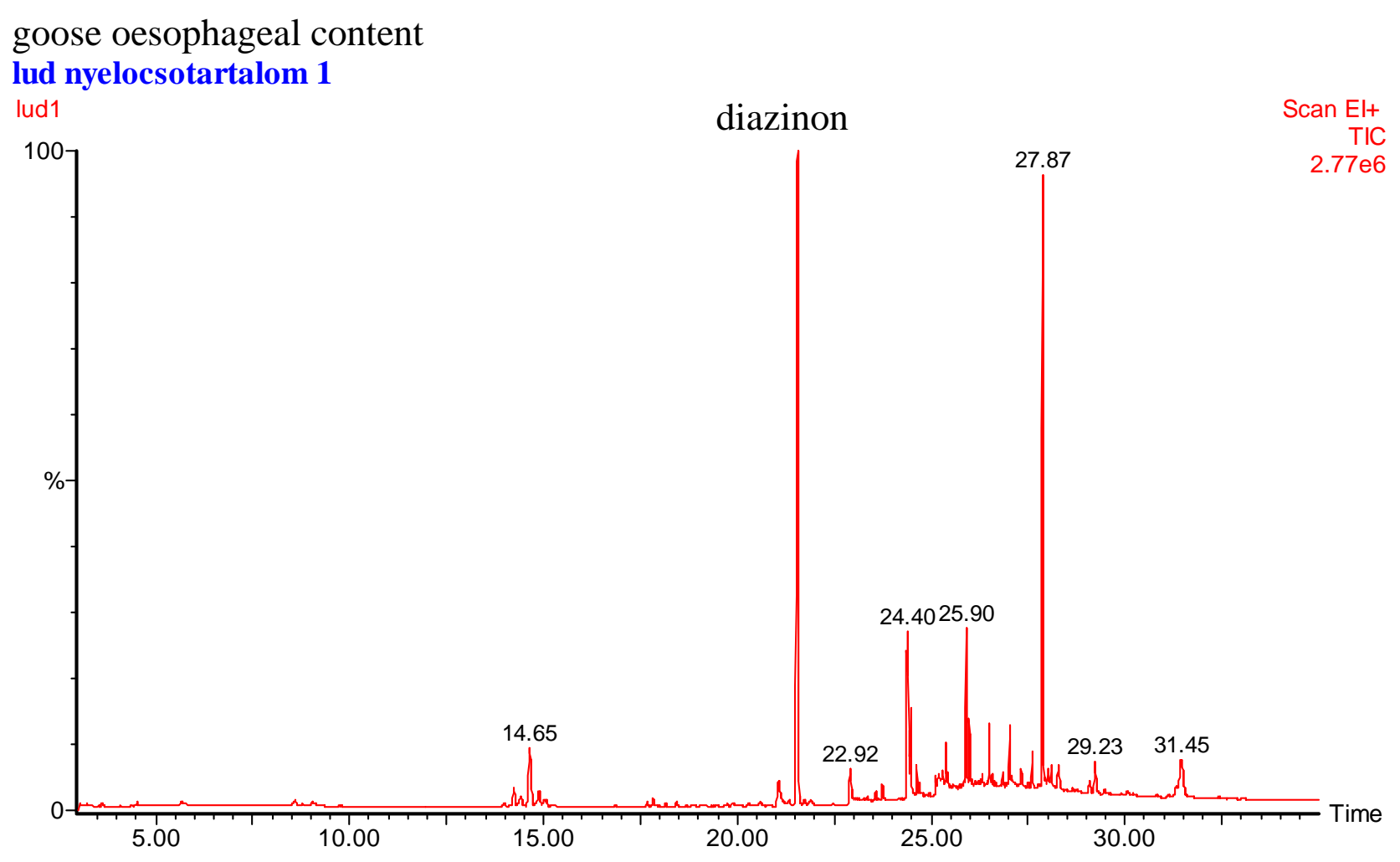

Fig. (1). GC-MS chromatogram of goose oesophageal content (Scan EI+; TIC); the peak located at 21:56 minutes corresponds to diazinon. 


\section{lud nyelocsotartalom 1 \\ lud1 2223 (21.556)}

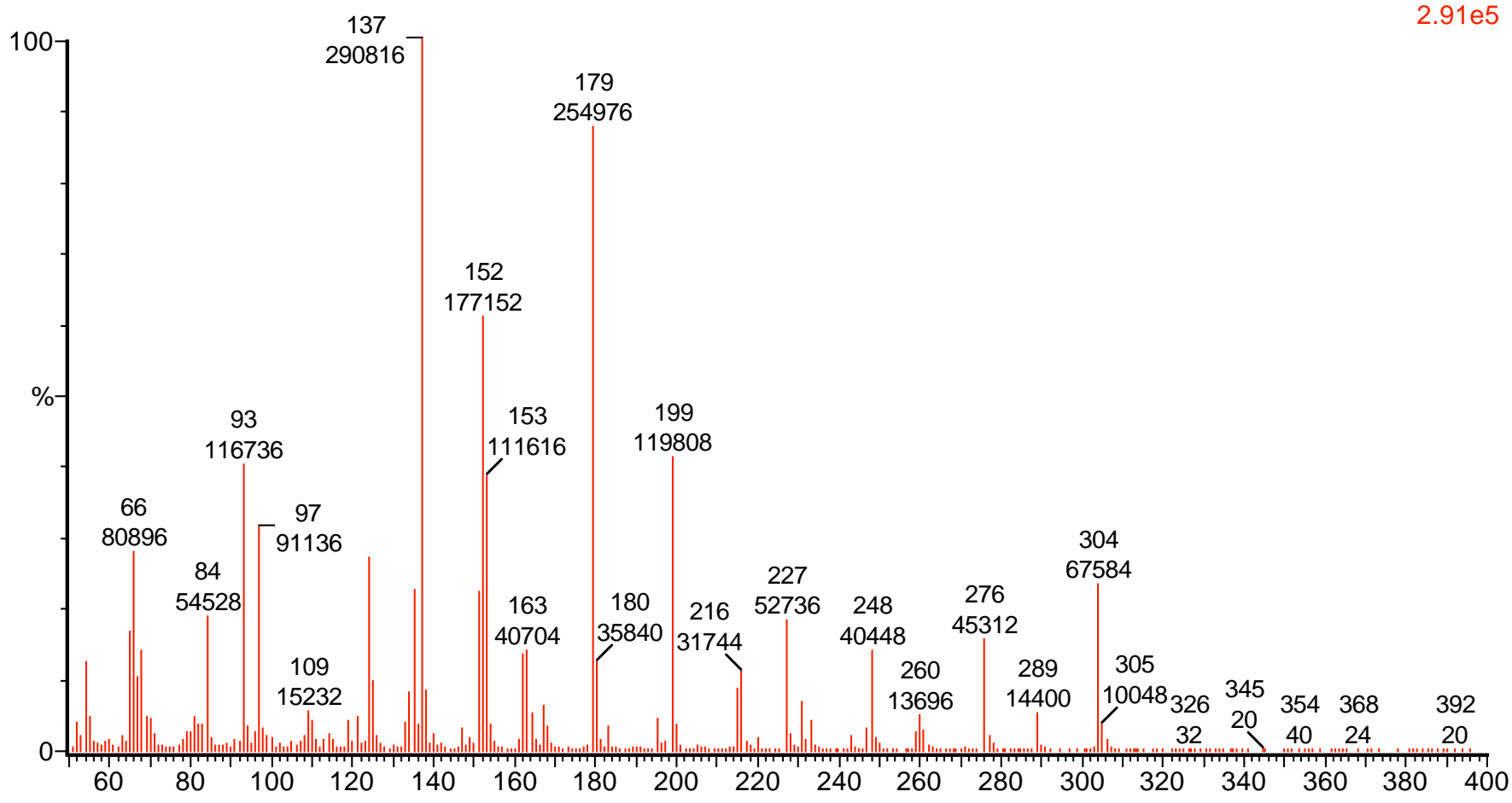

Fig. (2). The mass spectrum serving for the identification of diazinon (Rt: $21.556 \mathrm{~min}$ ).

were highly suggestive of poisoning. Toxicological analysis of the oesophageal content of goose carcasses and of the drinking water clearly demonstrated that this suspicion was well founded. Using a gas chromatograph equipped with mass spectrometric detector, diazinon was detected in concentrations of $22.1 \mathrm{mg} / \mathrm{kg}$ and $9.3 \mathrm{mg} / \mathrm{kg}$ in the oesophageal content and in concentrations of $807 \mathrm{mg} / \mathrm{l}$ and $582 \mathrm{mg} / \mathrm{l}$, respectively, in the drinking water samples. These are certainly significant levels, particularly those in the water, and relate to the known toxicity from diazinon $\left(\mathrm{LD}_{50}: 14.7\right.$ $\mathrm{mg} / \mathrm{kg}$ ) in avian species [7]. The high diazinon content of the water samples was indicative of accidental or intentional contamination. Diazinon is a highly toxic organophosphate compound, which is the active ingredient of the Neocidol $600 \mathrm{EC}$ dip and of the pesticides Basudin 5G, Basudin 600EW, Diazinon 5G, Diazol 5G and Diazol 60EC. A1though the diazinon-containing product responsible for the poisoning could not be identified, based on the diazinon content of the above products the toxicosis was most likely caused by the Neocidol 600 EC dip or the Basudin 600 EW pesticide. Neocidol 600 EC dip is widely used for preventive treatment of psoroptic mange of sheep in Hungary. In the literature, natural cases of diazinon toxicity have been described in broiler chickens [4] and, of the wild waterfowl species, in Canada geese [5, 8, 9] and goslings [6]. In young, 3 -day-old chicks high mortality was observed [4]. Necropsy revealed lachrymation, diarrhoea, haemorrhages under the pleura and in the mucous membrane of the proventriculus, and ulceration of the proventriculus. Numerous yellow granules were found in the crop. The assayed crop contents contained $39 \mathrm{ppm}$ diazinon. The toxicity in that instance may have resulted from the ingestion of diazinon-impregnated granules used for litter treatment [4].
Experimental diazinon poisoning has been induced in several animal species including goslings. In the latter species, the antidotal efficacy of different doses of pralidoxime iodide and obidoxime dichloride against the clinical signs of poisoning was investigated. Pralidoxime at $100 \mathrm{mg} / \mathrm{kg}$ brought about a complete and speedy clinical recovery, while at lower doses ( 50 and $25 \mathrm{mg} / \mathrm{kg}$ ) it induced recovery in some of the poisoned goslings only. Obidoxime at 50 and $100 \mathrm{mg} / \mathrm{kg}$ delayed the death of some birds by several hours. At $100 \mathrm{mg} / \mathrm{kg}$, all goslings had transient signs of intoxication, which precluded the use of this compound as an antidote at higher doses [10].

\section{CONCLUSION}

Pesticides containing organophosphates including diazinon and diazinon-containing antiparasitic agents are widely used in plant cultivation and animal production. The regulations concerning the proper distribution, use and storage of these products are often not complied with. This increases the risk of poisoning, which could be reduced by more stringent supervision and control.

\section{ACKNOWLEDGEMENTS}

The authors thank Dr Gyula Dobos and Dr Lajos Jánki, Official Veterinarians, for their help with the on-the-spot examinations and observations.

\section{REFERENCES}

[1] Farage-Elawar M. Enzyme and behavioral changes in young chickens as a result of carbaryl treatment. J Toxicol Environ Health 1989; 26: 119-31.

[2] Brown TP, Julian RJ. In: Saif JM, Ed. Diseases of Poultry. Iowa, Iowa State Press, A Blackwell Publishing Company. 2003; 113359. 
[3] Ronald E. Diazinon hazards to fish, wildlife and invertebrates; A synoptic review. Biol Rep 1986; 85: 1-9.

[4] Hill DL, Hall CI, Sander JE, Fletcher OJ, Page RK, Davis SW. Diazinon toxicity in broilers. Avian Dis 1994; 38: 393-6.

[5] Stone WB, Knoch H. American brant killed on golf courses by diazinon. N Y Fish Game J 1982; 29: 95-6.

[6] Egyed MN, Malkinson M, Eilat A, Shlosberg A. Basudin (diazinon) poisoning in goslings. Refuah Veterin 1974; 31: 22-6.

[7] Wayland JH, Edward RL. Handbook of pesticide toxicology. San Diego, California, 1991.
[8]

Frank R, Mineau HE, Braun HE, Barker IK, Kennedy SW, Trudeau S. Deaths of Canada geese following spraying of turf with diazinon. Bull Environ Contam Toxicol 1991; 46: 852-8.

[9] Spinato MT, Wobeser GA, Leighton T, Blakley BR. Diazinon toxicity in Canada geese. Can Vet J. 1991; 32: 627.

[10] Schlosberg A, Egyed MN, Eilat A, Malkinson M, Preissler E. Efficacy of pralidoxime iodide and obidoxime dichloride as antidotes in diazinon-poisoned goslings. Avian Dis 1976; 20: 162-6.

Received: August 25, 2008

Revised: September 16, 2008

Accepted: September 29, 2008

(C) Fazekas et al.; Licensee Bentham Open.

This is an open access article licensed under the terms of the Creative Commons Attribution Non-Commercial License (http://creativecommons.org/licenses/by$\mathrm{nc} / 3.0 /$ ) which permits unrestricted, non-commercial use, distribution and reproduction in any medium, provided the work is properly cited. 